\title{
Progress Toward the Total Synthesis of Bielschowskysin: A Stereoselective [2+2] Photocycloaddition
}

\author{
Brandon Doroh and Gary A. Sulikowski \\ Department of Chemistry, Vanderbilt University, Nashville, Tennessee 37235
}

\section{Abstract}

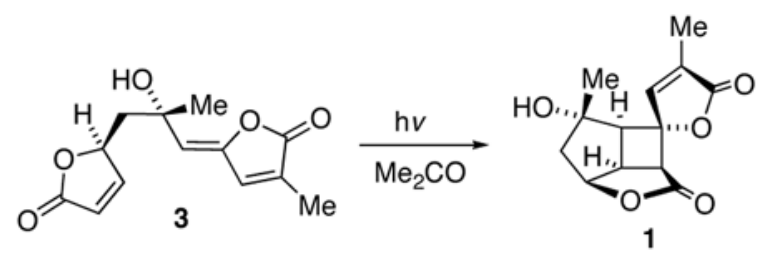

The tetracyclic core of the diterpene bielschowskysin has been prepared as a single enantiomer via astereoselective intramolecular [2+2] photocycloaddition of 5-alkylidene-2(5H)-furanone 3.

Gorgonian octacorals are the most plentiful source of octacorals in the West Indies. With over 190 documented species in this family, these marine organisms have proven to be an excellent source of biologically active metabolites. ${ }^{1}$ Recently there has been interest in the reef dwelling sea plume Pseudopterogorgia kallos as it has been shown to produce a wide range of structurally interesting diterpenes displaying a broad spectrum of bioactivities. ${ }^{2}$

Rodriguez and co-workers have reported the isolation of the novel diterpene bielschowskysin (Figure 1) from Pseudopterogorgia kallos collected near Old Providence Island off the coast of Columbia. ${ }^{3}$ Bielschowskysin is a highly oxygenated hexacyclic diterpene that incorporates 11 stereocenters (seven contiguous) and a novel [9.3.0.0 2,10$]$ tetradecane ring system. While the relative configuration has been established via X-ray crystal analysis, the absolute configuration has yet to be assigned.

Bielschowskysin demonstrated strong in vitro cytotoxicity against small cell lung cancer and renal cancer cells. ${ }^{3}$ Furthermore, it exhibits antiplasmodial activity against Plasmodium falciparum with an $\mathrm{IC}_{50}=10 \mu \mathrm{g} / \mathrm{mL}$. Owing to its intriguing architecture and our interest in the design of synthetic strategies for the purpose of investigating biological properties of natural products, we are currently exploring a route toward the synthesis of this diterpene and herein report the preparation of the tetracyclic core (1) of bielschowskysin employing a stereoselective intramolecular [2+2] photocycloaddition.

We reasoned that the congested tetracyclic intermediate $\mathbf{1}$ would be a good candidate for construction via an intramolecular [2+2] photocycloaddition of the appropriate 5-alkylidene-2 (5H)-furanone 2 (Scheme 1). Here, a key issue to be addressed was the stereoselectivity of the photocycloaddition and its dependence on the starting double bond geometry (vis á vis $\mathbf{2}$ and $\mathbf{3}$ ). In the forward sense the Z-olefin $\mathbf{3}$ would be readily accessed by a silver catalyzed cycloisomerization of eneyne $\mathbf{4}$. Irradiation of $\mathbf{3}$ was anticipated to rapidly lead to a mixture of double bond isomers 2 and $3{ }^{4}$ The overall stereoselectivity of the cycloaddition, particularly 
the configuration of the C6 quaternary carbon (cf. 1), would need to be determined by experimentation. The carboxylic acid $\mathbf{4}$ was anticipated to be generated from alkynyl alcohol 5 which itself may be prepared from (-)-malic acid.

The ester $\mathbf{6}$ has been prepared previously starting from malic acid and served as the starting point for the synthesis. 5 It was converted directly to the methyl ketone 7 via in situ formation of the Weinreb amide and reaction with methyl magnesium bromide. ${ }^{6}$ Chelation controlled addition of ethynyl magnesium bromide to ketone 7 was achieved in good yield and selectivity to provide a 4:1 mixture of alcohols $\mathbf{5}$ and $\mathbf{8}$.

As our synthetic strategy developed we required protection of the tertiary and secondary alcohols of $\mathbf{5}$, and unique differentiate of the remaining primary alcohol. Meyers and coworkers reported treatment of an acetonide protected triol, related to $\mathbf{5}$, with mesitaldehyde dimethylacetal under acidic conditions led to exchange of the acetonide group for a 1,3-dioxane leaving the primary alcohol uprotected. ${ }^{7}$ Indeed, treatment of $\mathbf{5}$ with camphorsulfonic acid and mesitaldehyde dimethylacetal affected exchange of the five-membered acetonide ring for 1,3dioxane acetal to give alcohol 9 with the desired protecting group pattern.

Silyl protection of the primary alcohol 9 was undertaken in order to examine elaboration of the terminal acetylene to the $\gamma$-alkylidene butenolide moiety. This was to be followed by release of the primary alcohol and construction of the second butenolide ring (cf. 3, Scheme 1). To this end, Sonogashira coupling with Z-vinyl iodide $\mathbf{1 1}^{8}$ was followed by a standard two-step oxidation leading to carboxylic acid 13. Silver catalyzed cyclization yielded $\gamma$-alkylidene buteneolide $\mathbf{1 4}$ as a crystalline solid. ${ }^{9} \mathrm{X}$-ray analysis of this product confirmed the assigned configuration of the stereocenter resulting from the alkyne addition to ketone $\mathbf{7}$ as well as the double bond geometry of the $\gamma$-alkylidene butenolide produced from the cycloisomerization of 13. Unfortunately, elaboration of alcohol $\mathbf{1 4}$ to butenolide $\mathbf{3}$ proved to be difficult and this approach to $\mathbf{3}$ was abandoned.

A second approach to bis-butenolide 3 that circumvents difficulties encountered in our first reaction sequence is shown in Scheme 4. Experience demonstrated that early Still-Gennari olefination 10 resulted in higher yields and stereoselectivity when compared to olefination reactions after construction of the $\gamma$-alkylidene butenolide (vide supra). Also, delayed completion of the butenolide avoided undesired Michael addition of the tertiary alcohol to the neighboring butenolide. Therefore, Z-enoate 16 was directly subjected to Sonogashira coupling conditions to yield allylic alcohol 17. Consecutive oxidations afforded the carboxylic acid 18 in acceptable overall yield. Silver nitrate catalyzed cyclization under Negeshi's conditions afforded alkylidene buteneolide $\mathbf{1 9}$ as a single geometric isomer. Finally, treatment of mesitylene acetal 19 with aqueous acetic acid at room temperature led to butenolide formation and completion of $\mathbf{3}$.

Irradiation of a chloroform solution of $\mathbf{3}$ with a sun lamp for 2 hours led to an approximately 3.6:1 mixture of geometric isomers $\mathbf{3}$ and $\mathbf{2}$ as determined by ${ }^{1} \mathrm{H}$ NMR analysis. Continued irradiation of a chloroform solution of $\mathbf{3}$ and $\mathbf{2}$ resulted in consumption of both isomers and production of a complex mixture of products. Upon replacing chloroform with acetone, a similar equilibration-cyclization sequence was observed on irradiation with a sun lamp; however, in this case far fewer side products were observed. Moreover, a 5:1 mixture of [2+2] photoadducts was isolated in 50\% yield with the major product assigned the structure of the desired photoadduct $\mathbf{1}$. Initially the stereochemical assignment of $\mathbf{1}$, and most significantly the C6 sterecenter, rested on an observed nOe between the beta hydrogen of the butenolide and the endo oriented methyl group. The assignment of $\mathbf{1}$ was later confirmed by single-crystal Xray analysis (Scheme 4). 
The intramolecular [2+2] photocycloaddition of butenolides $\mathbf{2}$ and $\mathbf{3}$ likely follows the so-called rule of five leading to intermediate 1,4-biradicals $\mathbf{2 a}$ and $\mathbf{3 a}$ (Figure 2), respectively. ${ }^{11}$ Weedon and Maradyn who trapped triplet 1,4-biradicals using hydrogen selenide provided evidence for the intermediacy of 1,4-biradicals and the appropriateness of the rule of five in intramolecular photocycloadditions. ${ }^{12}$ Extending this model to substrates $\mathbf{2}$ and 3, triplet 1,4-biradicals $\mathbf{2 a}$ and $3 \mathbf{a}$ could interchange by one of two mechanisms. First, simple bond rotation could lead to rapid interconversion of triplet biradicals $\mathbf{2 a}$ and $\mathbf{3 a}$. A second pathway involves simple reversion of $\mathbf{2 a}$ and 3a to starting $\gamma$-alkylidene butenolides $\mathbf{2}$ and $\mathbf{3}$, respectively, which our photochemical experiments showed interchange by simple photoisomerization. By either of these two mechanisms the favored production of photoadduct $\mathbf{1}$ by closure of $\mathbf{2 a}$ may be explained by the development of unfavorable dipole and/or electrostatic interactions in the alternative closure of 1,4-biradical 3a to 20.13

In conclusion we have described a concise and stereocontrolled assembly of the tetracyclic core (1) of the marine diterpene bielschowskysin. Current efforts are directed toward completion of the total synthesis of bielschowskysin using the reported photocycloaddition as a key step.

\section{Supplementary Material}

Refer to Web version on PubMed Central for supplementary material.

\section{Acknowledgements}

We thank the National Institutes of Health (GM067726-02) and the Vanderbilt Institute of Chemical Biology for financial support. We also thank Joseph Reibenspies (Center for Chemical Characterization and Analysis, Texas A\&M University) for determining the X-ray crystal structures of $\mathbf{1}$ and $\mathbf{1 4 .}$

\section{References}

1. Review: Rodriquez AD. Tetrahedron 1995;51:4571-4618.

2. (a) Look SA, Burch MT, Fenical W. J Org Chem 1985;50:5741-5746. (b) Marrero J, Rodriguez AD, Baran P, Raptis RG. J Org Chem 2003;68:4977-4979. [PubMed: 12790615] (c) Marrero J, Rodriguez AD, Baran P, Raptis RG. Org Lett 2003;5:2551-2554. [PubMed: 12841778] (d) Marrero J, Rodriguez AD, Baran P, Raptis RG. Eur J Org Chem 2004:3909-3912.

3. Marrero J, Rodriguez AD, Baran P, Raptis RG, Sánchez JA, Ortega-Barria E, Capson TL. Org Lett 2004;6:1661-1664. [PubMed: 15128261]

4. (a) Brown GD, Wong HF. Tetrahedron 2004;60:5439-5451. (b) Gedge DR, Pattenden G, Smith AG. J Chem Soc Perkin Trans 1 1986:2127-2131.

5. Saito S, Hasegawa T, Inaba N, Nishida R, Fujii T, Nomizu S, Muriwake T. Chem Lett 1984:13891392.

6. (a) Mori Y, Kuhara M, Takeuchi A, Suzuki M. Tetrahedron Lett 1988;29:5419-5433. (b) Mori Y, Suzuki M. J Chem Soc Perkin Trans 1 1990:1809-1812.

7. Meyers AJ, Lawson JP, Walker DG, Linderman PJ. J Org Chem 1986;57:5111-5123.

8. Duboudin JG, Jousseaume B, Bonakdar A. J Organomet Chem 1979;168:227-238.

9. (a) Kotora M, Negishi E. Synthesis 1997:121-128. For a review on the synthesis of $\gamma$-alkylidene butenolides see: (b) Negishi E, Kotora M. Tetrahedron 1997;53:6707.

10. Still WC, Gennari C. Tetrahedron Lett 1983;24:4405-4408.

11. (a) Liu RS, Hammond GS. J Am Chem Soc 1967;89:4936-4944. (b) Carlough KH, Srinivasa R. J Am Chem Soc 1967;89:4932-4936.

12. Maradyn DJ, Weedon AC. J Am Chem Soc 1995;117:5359-5360.

13. Crimmins MT, King BW, Watson PS, Guise LE. Tetrahedron 1997;53:8963-8974. 


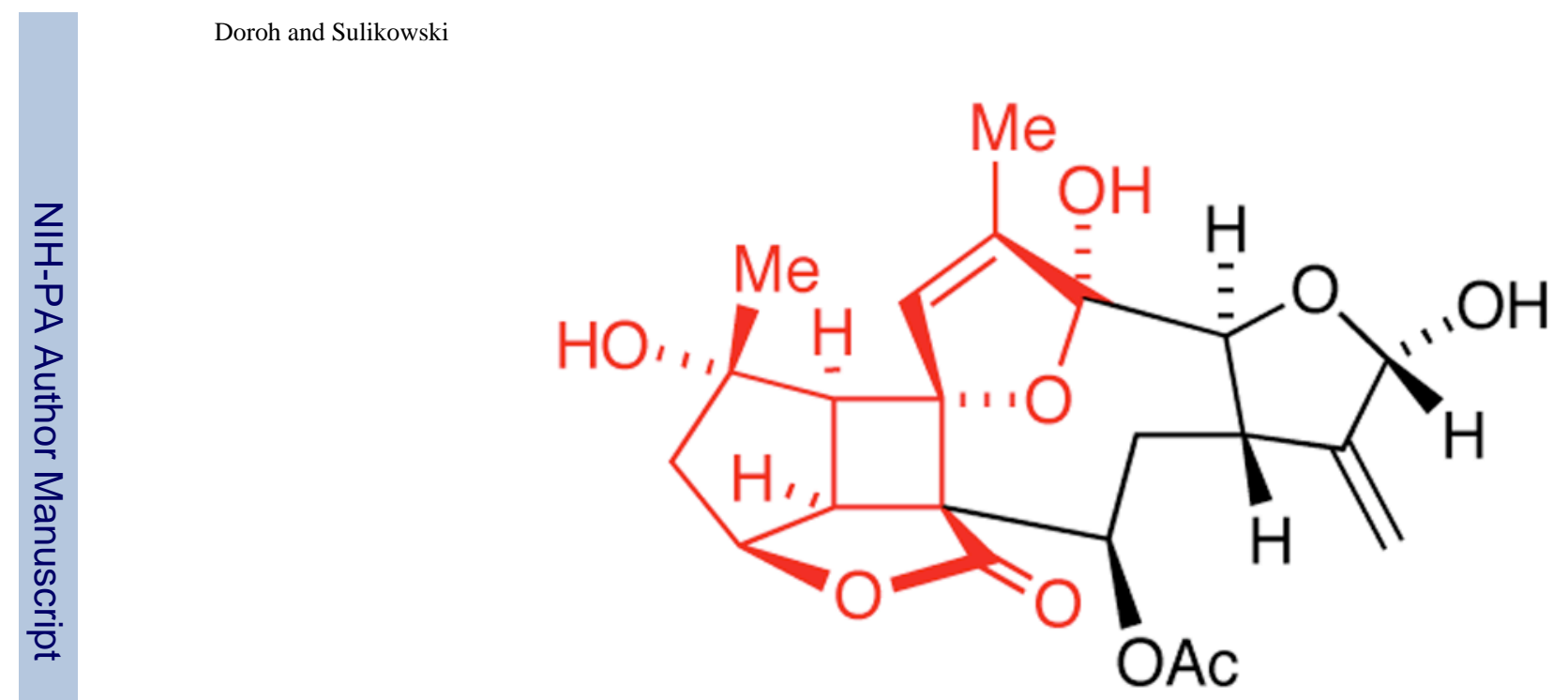

Figure 1.

Structure of bielschowskysin. 
<smiles>Cc1c/c(=C\[C@@](C)(O)C[C@H]2C=CC(=O)O2)o/c1=C\[C@@](C)(O)C[C@@H]1C=CC(=O)O1</smiles>

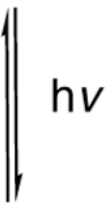

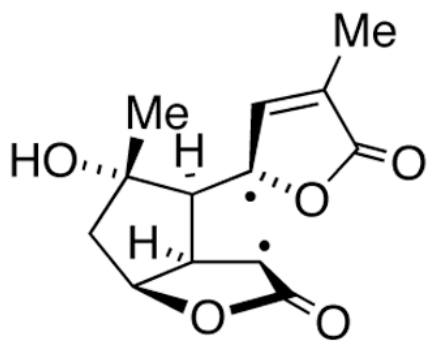

2a

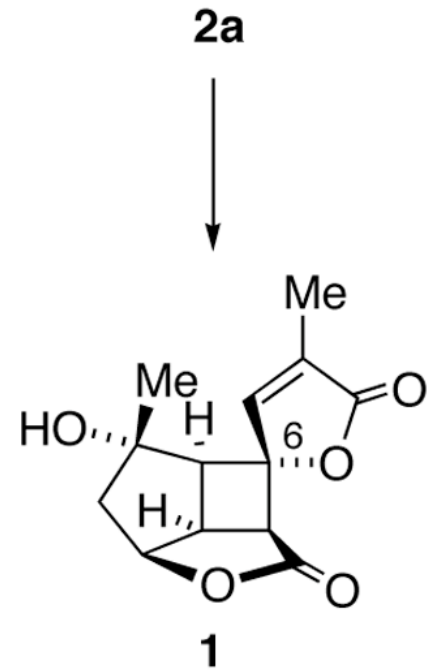

1

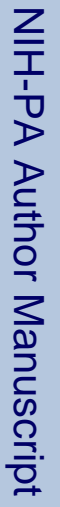

Figure 2.

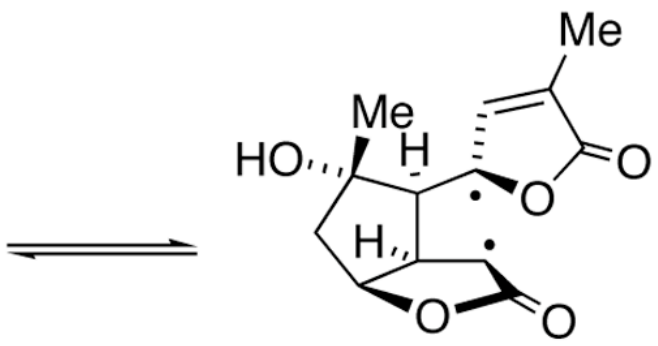

3

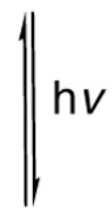

3a

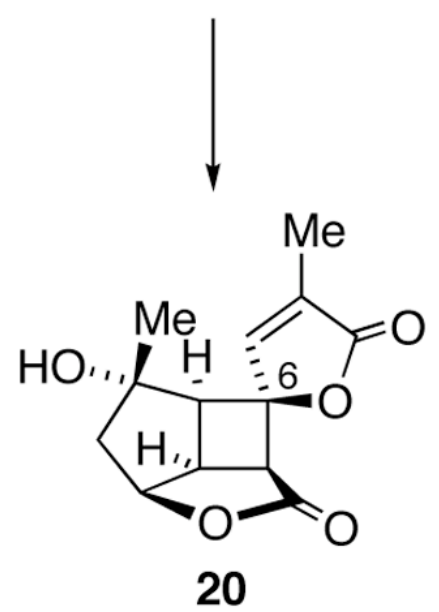

Model for observed diastereoselectivity of [2+2] photocycloaddition. 

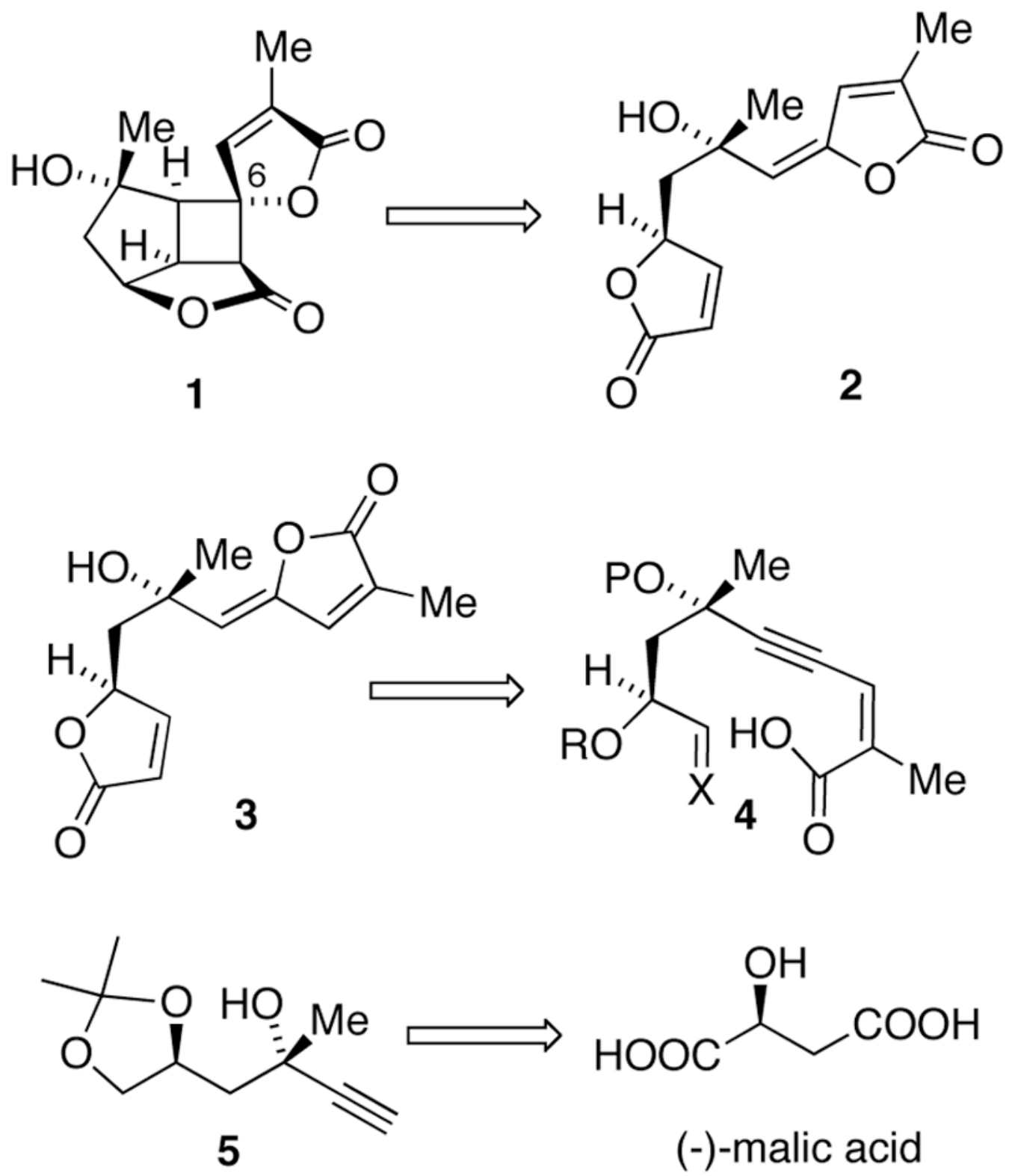

Scheme 1. 
<smiles>COC(=O)C[C@@H]1COC(C)(C)O1</smiles><smiles>C#C[C@](C)(O)C[C@@H]1COC(C)(C)O1</smiles><smiles>CCCCCCCCCCCCC(C)C</smiles><smiles>C#C[C@]1(C)C[C@H](CO)O[C@@H]([As])O1</smiles>

Scheme 2. 
<smiles>[2H]OC[C@H]1C[C@@](C)(C#C)O[C@H]([As](C)(=O)=O)O1</smiles>

TBSOTf

$9 \mathrm{R}=\mathrm{H}$

2,6-lutidine
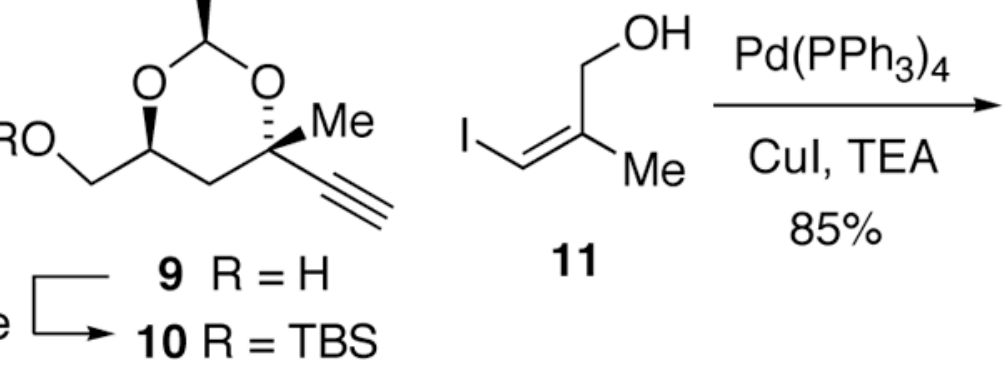

11
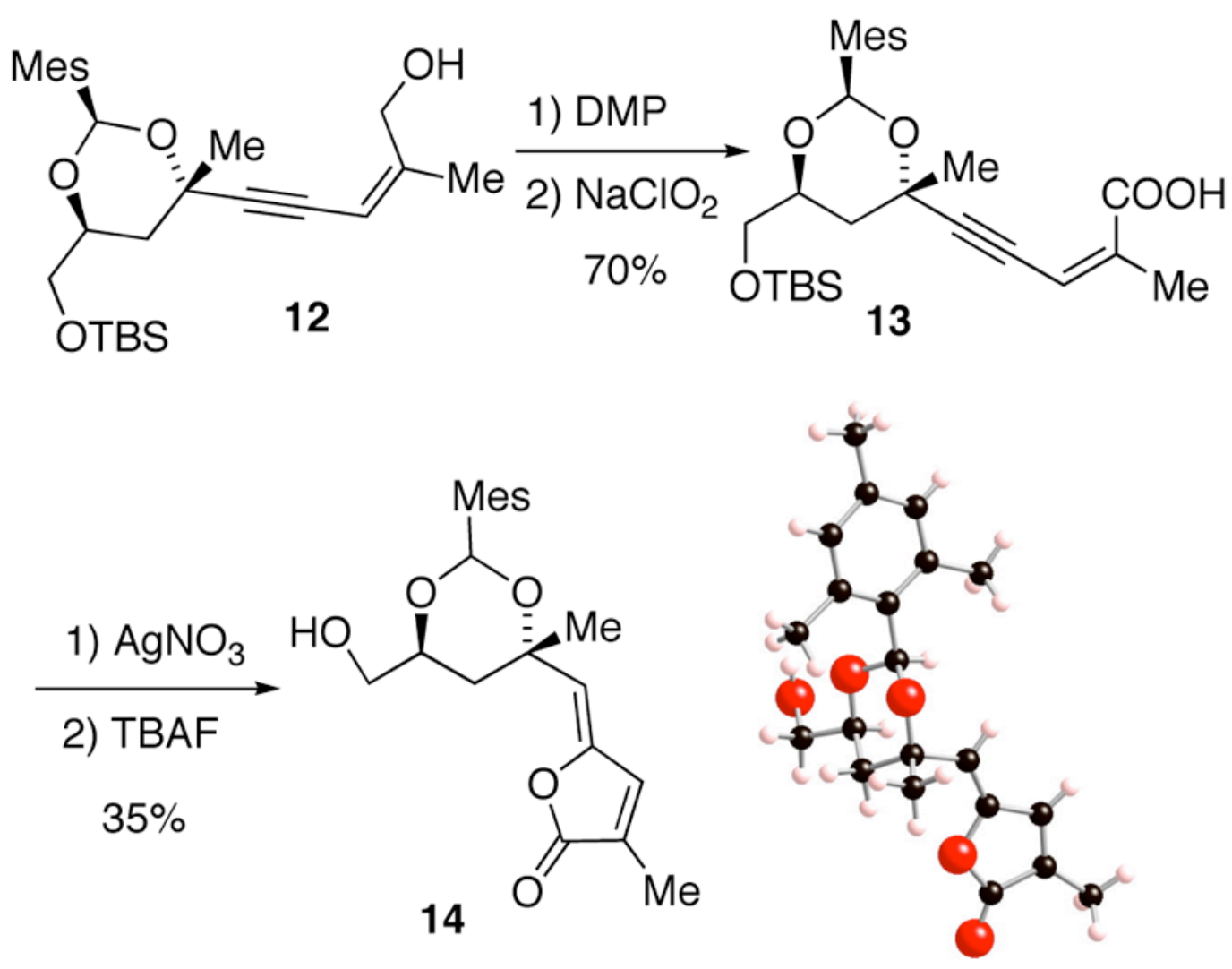

Scheme 3. 
<smiles>[X]C=CC1C[C@](C)(C#C)O[C@@H](C)O1</smiles>

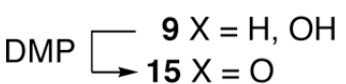

16

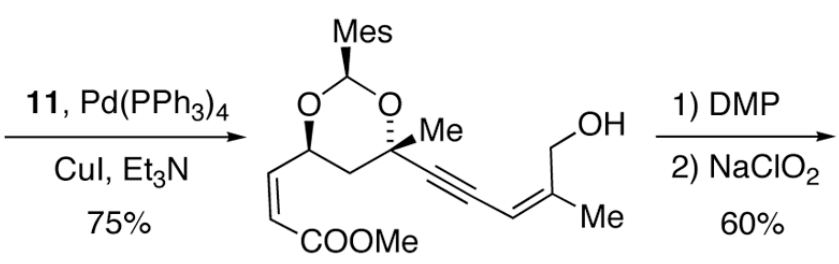

17

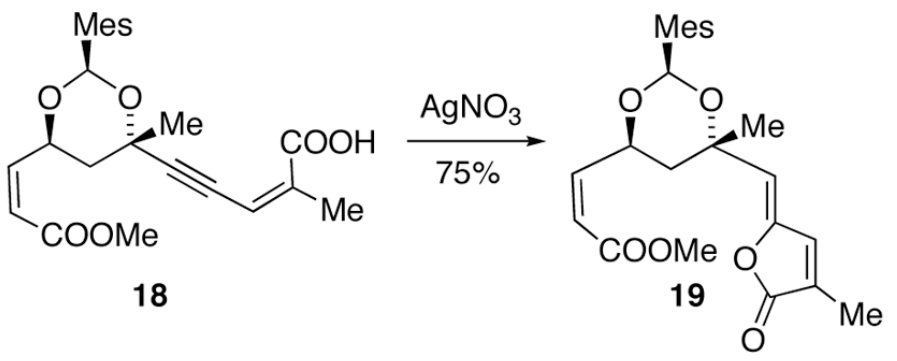<smiles>Cc1cc(=C[C@@](C)(O)C[C@H]2C=CC(=O)O2)oc(=O)c1=CC(=O)O</smiles>
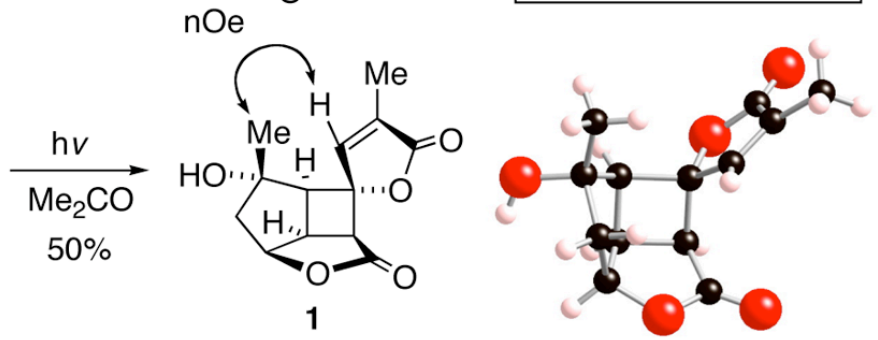

Scheme 4. 